\title{
BMJ Global Health Lost in translation: a caution against using automated and commercial translation services for medical communications
}

\author{
Sanita Kaur Sandhu (D) , ${ }^{1,2}$ Niki Kouvroukoglou, ${ }^{2}$ Marina Campodonico, ${ }^{3}$ \\ Felicity Mehendale ${ }^{4}$
}

To cite: Sandhu SK, Kouvroukoglou N, Campodonico M, et al. Lost in translation: a caution against using automated and commercial translation services for medical communications. BMJ Global Health 2022;7:e008067. doi:10.1136/ bmjgh-2021-008067

Handling editor Seye Abimbola

Received 28 November 2021 Accepted 7 December 2021

Check for updates

(c) Author(s) (or their employer(s)) 2022. Re-use permitted under CC BY-NC. No commercial re-use. See rights and permissions. Published by BMJ.

${ }^{1} \mathrm{NHS}$ Lothian, Edinburgh, UK ${ }^{2}$ School of Molecular and Clinical Medicine, The University of Edinburgh, Edinburgh, UK ${ }^{3}$ Odontología, Universidad de Chile, Santiago de Chile, Chile ${ }^{4}$ Usher Institute of Population Health Sciences and Informatics, The University of Edinburgh, Edinburgh, UK

Correspondence to Dr Sanita Kaur Sandhu; sanitasandhu@doctors.org.uk
Medical terminology is continually evolving. Anachronistic terms such as "hermaphrodite" have been removed from medical nomenclature and replaced with "intersex person". Reiter's syndrome is now named reactive arthritis, to distance from Nazi physician Hans Reiter and there are calls for nonalcoholic fatty liver disease to be renamed metabolic fatty liver disease. ${ }^{1}$ All are examples where stigmatisation, trivialisation and less consideration of the disease in health policy are associated with the nomenclature used to describe the disease. 'Harelip' is a means to describe 'cleft lip' is no different. Thought to be consigned to the past as an offensive term, 'harelip' is a term to describe an individual with a congenital split in their lip and/ or palate (CLP). Cleft lip and cleft palate are accepted modern terms. We conducted a CLP research exercise that required the use of Google Translate to translate documents into French and Spanish. Google Translate translated 'cleft lip' to 'harelip' in multiple European languages including Spanish, Dutch, Greek and Polish. Thus, this paper discusses the history and issues of 'harelip' as terminology and the associated pitfalls of using modern translation services for medical communications.

Galen was the first physician to use lagochelios, or 'lip like a hare' to describe a cleft lip. ${ }^{2}$ Ambroise Paré, a French surgeon popularised this term in 1575 and bec-de-lievre or "hare lip' became the accepted term for cleft lip. ${ }^{2}$ Through the Middle Ages, harelip was associated with negative connotations. The Archbishop of Sweden Olaus Magnus believed that pregnant women who bore children with 'hare mouths' must have eaten or lept over the head of a hare. ${ }^{3}$ This extended to members of the medical profession as Lorenz Heister,
Summary box

'Harelip' is a derogatory term to describe individuals with cleft lip $+/-$ and can contribute to ongoing stigma surrounding this condition.

- Automated translation services and human translators may be unaware of medically offensive terms.

- Thus, checking any documents by a native speaker with knowledge of the clinical field is essential.

- As medical terminology evolves, medical societies should publish a list of appropriate as well as outdated terms, to avoid causing offence and distress in medical communications.

German anatomist and surgeon in wrote in 1731- It causes not only great ugliness of the face but also.... if the cleft is large, such people even when the harelip has already been healed, cannot help speaking nastily and unacceptably through their nose for the term of their life". ${ }^{4}$ It was not only until 1922 that a clarion call for abandoning the use of the term hare lip was sounded at the American Medical Association in St Louis. ${ }^{5}$ Since then, systems to classify cleft lips use their embryologic, genetic or biochemical foundations.

Despite this change in nomenclature, the social stigma attached to craniofacial conditions still exist. Young people with CLP may have multiple functional and aesthetic problems including trouble closing their mouth, feeding difficulties, hearing difficulties and speech difficulties. Due to these difficulties, teasing and bullying are two major problems in the life of a young person with CLP. ${ }^{6}$ Taunting often begins at school and is directed towards the physical appearance of the child with the dangerous consequences of causing anxiety, depression and in the worst cases, suicide. ${ }^{6}$ These psychological issues may persist into adulthood, although there 
is evidence to suggest that the self-perception and selfesteem of patients with CLP improve over time. One study suggests this may be due to increased self-acceptance and the definitive surgical correction being available during adulthood. ${ }^{7}$ We know that patients with CLP are bullied but the incidence of bullying using the word 'harelip' has not been reported in the literature. Anecdotal evidence supports that people with CLP are often called 'harelip' in a derogatory manner. Cleft Lip and Palate Association suggest avoiding this term unless the individual with CLP uses it to describe themselves. ${ }^{8}$

With individuals with cleft lip and palate still subjected to such stigma, using an offensive term like harelip potentially increases this. As part of a global research priority setting exercise in cleft palates, participant information sheets were translated into Spanish and French using Google Translate. These sheets were proofread by native speakers who were also cleft clinicians. Our Spanish colleague highlighted that the translation of 'Labio leporino' was an offensive term and was translated to English as 'harelip'. Instead, the term 'labio hendido/ fisurado' (depending on geographical location) for cleft lip and 'paladar hendido/fisurado' for cleft palate was preferable. Fortunately, the French translation of 'fente labiale' for cleft lip and 'cleft palatine' for cleft palate translated correctly. We, therefore, decided to run through 'cleft lip' in Google Translate and found that several results translated it to variations of 'harelip'. In Dutch, the translation was 'hazenlip', in Greek ' $\lambda \alpha \gamma o ́ \chi \varepsilon ı \lambda 0^{\prime}$ ( lagócheilo) and Polish 'zajęcza warga'.

We used Google Translate as a translation tool for our exercise. Originally launched in 2006, Google Translate works through translating pieces of text into English and back into the desired language with references to millions of documents taken from historical official United Nations transcripts. It uses statistical matching as opposed to complex grammars for each language. In November 2016, Google announced a transition to neural machine translation, a 'deep learning' tool that would regularly compare whole sentences at a time from many linguistic sources to learn language quirks and idioms. ${ }^{9}$ Despite this improvement, Patil and Davies ${ }^{10}$ found serious errors in translations of common medical phrases. Ten common phrases were translated using Google Translate into 26 languages after which a native human speaker assessed their accuracy. Of the total translations, $150(57.7 \%)$ were correct and 110 (42.3\%) were wrong. Western European languages were most accurate and African languages least. Some serious errors included a translation of Your child is fitting in English to Your child is dead in Swahili. Another paper assessed the accuracy of Google Translate to allow data extraction from trials published in a nonEnglish language and found that accuracy was about $76 \%$ across all languages. ${ }^{11}$ This shows while Google Translate is a useful, free tool, it does not always reflect the evolution of appropriate clinical terms.

Interestingly, the same error was noted when we sent the participant information sheets to an international, professional translation service, which used the term 'Labio leporino' to describe CLP.

Person-centred, sensitive revision of historical terms for medical conditions is a welcome change and continually evolving process. Automated translation services and even human translators may be unaware of such nuances and the potential to cause offence and distress. Thus, checking any medical translation by a native speaker with knowledge of the relevant clinical field is essential. Additionally, we suggest that as medical terminology evolves, international medical societies publish, on a publicly available site, a list of appropriate, as well as outdated terms, in multiple languages, as a continually updated resource. We plan to publish such a list for cleft lip and palate.

Correction notice This article has been corrected since it published online to reflect the correct contributor statement.

Contributors FM created the concept for the paper. FM created the outline for the paper. SKS developed the idea. SKS wrote the report with support from NK, MC and FM. All authors contributed ideas and edits to the manuscript. FM supervised the overall project.

Funding The authors have not declared a specific grant for this research from any funding agency in the public, commercial or not-for-profit sectors.

Competing interests None declared.

Patient consent for publication Not applicable.

Ethics approval This study does not involve human participants.

Provenance and peer review Not commissioned; internally peer reviewed.

Data availability statement There are no data in this work.

Open access This is an open access article distributed in accordance with the Creative Commons Attribution Non Commercial (CC BY-NC 4.0) license, which permits others to distribute, remix, adapt, build upon this work non-commercially, and license their derivative works on different terms, provided the original work is properly cited, appropriate credit is given, any changes made indicated, and the use is non-commercial. See: http://creativecommons.org/licenses/by-nc/4.0/.

ORCID iD

Sanita Kaur Sandhu http://orcid.org/0000-0003-1135-9943

\section{REFERENCES}

1 Fouad Y, Waked I, Bollipo S, et al. What's in a name? Renaming 'NAFLD' to 'MAFLD'. Liver International 2020;40:1254-61.

2 Bhattacharya S, Khanna V, Kohli R. Cleft lip: the historical perspective. Indian J Plast Surg 2009;42 Suppl:S4-8.

3 Magnus O. (Archibiscopus upsaliensis) Historia de gentibus septentrionalibus. 1535. Roma: De Leporum Varietate, 1935.

4 Bill J, Proff P, Bayerlein T, et al. Treatment of patients with cleft lip, alveolus and palate--a short outline of history and current interdisciplinary treatment approaches. J Craniomaxillofac Surg 2006;34 Suppl 2:17-21.

5 Allori AC, Mulliken JB, Meara JG, et al. Classification of cleft lip/ palate: then and now. Cleft Palate Craniofac J 2017;54:175-88.

6 Winsper C, Lereya T, Zanarini M, et al. Involvement in bullying and suicide-related behavior at 11 years: a prospective birth cohort study. J Am Acad Child Adolesc Psychiatry 2012;51:271-282.e3.

7 Nicholls W, Selvey LA, Harper C, et al. The psychosocial impact of cleft in a Western Australian cohort across 3 age groups. Cleft Palate Craniofac J 2019;56:210-21.

8 Association CL and P. CLAPA Language and Style Guide for Staff Language and Style Guide [Internet], 2019. Available: https://www. clapa.com/wp-content/uploads/2020/03/Language-Style-Guide.pdf

9 Wu Y, Schuster M, Chen Z. Google's Neural Machine Translation System: Bridging the Gap between Human and Machine Translation, 2016. Available: http://arxiv.org/abs/1609.08144

10 Patil S, Davies P. Use of Google translate in medical communication: evaluation of accuracy. BMJ 2014;349:g7392. 
11 Balk EM, Chung M, Chen ML, et al. Data extraction from machinetranslated versus original language randomized trial reports: a comparative study. Syst Rev 2013;2:97. 